\title{
O EMPREGO DE REDES NEURAIS ARTIFICIAIS NA DETECÇÃO, CLASSIFICAÇÃO E LOCALIZAÇÃO DE FALTAS EM LINHAS DE TRANSMISSÃO
}

\author{
M. Oleskovicz* \\ olesk@sel.eesc.sc.usp.br
}

\author{
D. V. Coury* \\ coury@sel.eesc.sc.usp.br
}

\author{
R. K. Aggarwal ${ }^{\dagger}$ \\ R.K.Aggarwal@bath.ac.uk \\ *Departamento de Engenharia Elétrica, Universidade de São Paulo, Av. Dr. Carlos de Botelho, 1465 \\ São Carlos SP, Brasil. \\ ${ }^{\dagger}$ School of Electronic and Electrical Engineering, University of Bath, Bath BA2 7AY, UK.
}

\begin{abstract}
This study has as objective the application of Artificial Neural Networks (ANNs) theory as pattern classifiers. The implemented neural networks acquire knowledge for the detection, classification and localization of the fault facing different network conditions. The neural networks were implemented using NeuralWorks software. In this approach the three-phase voltage and current pre and post-fault values were utilized as inputs, for training and test purposes. The Alternative Transients Program (ATP) software was used to generate data for the transmission line $(440 \mathrm{kV})$ in a faulted condition, both for the purposes of training and tests. The results obtained showed that the global performance of the ANN architectures is highly satisfactory for fault detection, classification and localization purposes. Considering all the studied cases, the ANN outputs converged to the correct levels very rapidly after fault occurrence.
\end{abstract}

KEYWORDS: Electric power systems, fault detection, classification and localization, artificial neural networks (ANNs).

Artigo submetido em 20/12/00

1a. Revisão em 22/11/01; 2a. Revisão em 30/08/02

Aceito sob recomendação do Ed. Assoc. Prof. José L. R. Pereira

\section{RESUMO}

Este estudo traz como objetivo a implementação de um sistema de proteção aplicando-se a teoria de Redes Neurais Artificiais (RNAs) como um classificador de padrões. As redes neurais adquirem o conhecimento para a deteç̧ão, classificação e localização da falta frente às diferentes situações apresentadas sobre o sistema e foram implementadas através da aplicação do software NeuralWorks. As arquiteturas de RNAs empregam os valores amostrados das tensões e correntes trifásicas de pré e de pós-falta tanto para o processo de treinamento como para o de testes. O software ATP (ATERNATIVE Transients Program, 1987) é utilizado para gerar os dados referentes à linha de transmissão $(440 \mathrm{kV}) \mathrm{em}$ condições de falta para ambos os processos (treinamento e teste). Os resultados obtidos mostram que o desempenho global das arquiteturas de RNAs implementadas são altamente satisfatórios para a detecção, classificação e localização de situações faltosas em um sistema de transmissão. De todos os casos considerados na fase de teste, as saídas apresentadas pelas arquiteturas mostram uma convergência rápida para os níveis requeridos após a ocorrência da falta.

PALAVRAS-CHAVE: Sistemas elétricos de potência, detecção, classificação e localização de faltas, redes neurais 
artificiais (RNAs).

\section{INTRODUÇÃO}

A função de um sistema de proteção é promover a remoção imediata de qualquer seção com falta em sua zona de proteção pela atuação apropriada dos seus disjuntores, minimizando a interrupção do serviço de fornecimento de energia e limitando os danos aos equipamentos.

Dentre os componentes de um sistema elétrico de potência, a linha de transmissão é o elemento mais susceptível a faltas, especialmente se considerarmos as suas dimensões físicas. A prática demonstra que entre $70 \%$ e $80 \%$ das faltas nas linhas de transmissão ocorrem entre um só condutor e a terra. Um menor número de faltas referese as que envolvem todas as três fases, em torno de $5 \%$ (Stevenson, 1986).

Para a proteção de linhas de transmissão, diferentes tipos de relés convencionais são utilizados. Os mais freqüentemente empregados referem-se aos relés eletromecânicos, de estado sólido e mais recentemente os digitais. Estes respondem baseados na impedância observada entre a localização do relé e a falta, determinando se a falta é interna ou externa a uma determinada zona de proteção. No caso das linhas de transmissão, utilizam-se convencionalmente os valores das tensões e correntes trifásicas registrados para detectar, classificar e localizar determinada falta e então enviar um sinal para os circuitos de interrupção que irão desconectar a linha faltosa. Em um sistema interconectado, o sistema de transmissão restante poderá então operar normalmente ou pelo menos trabalhar o mais próximo possível das condições normais.

Frente às considerações apresentadas, para a implementação de um modelo completo de proteção de distância para linhas de transmissão é necessária, como primeiro passo, a detecção do defeito, ou seja, da situação de falta. Seguindo a esta, a confirmação e discriminação das fases envolvidas na falta (classificação) e finalmente a localização da mesma no que diz respeito à verificação das zonas de proteção deve ser efetuada. Assim, após esta seqüência de operações, haverá ou não a atuação dos disjuntores, quando conveniente.

Com os recentes avanços relacionados às técnicas de Inteligência Artificial, especificamente a teoria de RNAs, encontram-se na literatura diferentes modelos desta natureza designados à solução de problemas específicos. A teoria de RNAs provê uma alternativa, usando técnicas inteligentes, aos algoritmos tradicionais empregando métodos determinísticos. Dillon \& Niebur (1996) apre- sentam uma avaliação geral da aplicação de RNAs em sistemas de potência. Relativo à aplicação em proteção de sistemas, alguns estudos, empregando-se o reconhecimento de padrões à proteção de distância, são encontrados em Khaparde et alii (1991), Chakravarthy et alii (1992), Dalstein et alii (1996), Coury \& Jorge (1998) e Coury \& Oleskovicz (1998). Referentes à detecção de uma situação de falta encontramos as pesquisas desenvolvidas por Kandil et alii (1992), Al-Hasawi et alii (1997) e Su et alii (1997), bem como para a discriminação direcional, os resultados apresentados por Sidhu et alii (1995). Para a localização de faltas podemos referenciar Kanoh et alii (1991) e Yang et alii (1994) e para a classificação de faltas para linhas de transmissão devem finalmente ser citados os trabalhos defendidos por Ghosh \& Lubkeman (1995), Dalstein \& Kuliche (1995), Kezunovic \& Rikalo (1996), Aggarwal et alii (1999) e Keerthipala et alii (1997).

Através da aplicação de RNAs, apresenta-se, no que segue, um método alternativo para a proteção de linhas de transmissão, baseado em modelos que realizem as suas funções em um tempo menor, quando comparados aos dispositivos convencionais e que sejam imunes a mudanças operacionais do sistema. O incentivo para a aplicação de tal ferramenta vem da possibilidade de classificarmos a atuação de um sistema de proteção, como um problema de reconhecimento de padrões. Trabalhando com a identificação e classificação da informação em categorias, acredita-se que seja possível detectar, classificar e localizar uma situação de falta utilizando-se da capacidade de generalização, abstração e tolerância a falhas, características estas inerentes a um sistema de redes neurais.

O software NeuralWorks (NeuralWorks Professional II/PLUS, 1998) é empregado neste estudo para implementar as topologias de RNAs, treinando-as com o objetivo de se obter as matrizes de pesos fixas, as quais contêm todas as informações sobre as operações presentes no sistema de transmissão. Estas matrizes são mantidas constantes após a conclusão do treinamento, ou seja, durante a execução da etapa de testes. O software provê um ambiente flexível para a pesquisa, bem como para a aplicação das técnicas que envolvem a teoria de RNAs.

Com relação ao sistema elétrico em condição faltosa, dispõe-se de simulações utilizando o software ATP para obtenção do conjunto de dados.

Destaca-se de que o objetivo de treinar os módulos de redes neurais é o de se obter as matrizes de pesos fixas (treinamento das RNAs, rotina off-line). Mantendo 
estas matrizes constantes, pode-se considerá-las através de um algoritmo computacional e obter as respostas desejadas sobre todas as prováveis condições de operação do sistema de transmissão.

Como será evidenciado nos próximos itens, considerando-se a freqüência de amostragem empregada $(1 \mathrm{kHz})$, estima-se um tempo médio computacional de todo o processo (detecção, classificação e localização) de 13 ms. Esta "rapidez" nas respostas esperadas sobre o sistema de proteção vem aliada a um considerável índice de acertos por parte das arquiteturas de RNAs implementadas.

No que segue, serão apresentadas algumas considerações adotadas para o treinamento e teste das arquiteturas destinadas ao módulos de detecção, classificação e de localização. Além destes apontamentos, a lógica seqüencial de um algoritmo computacional será apresentada. Este algoritmo computacional, implementado em linguagem de programação "C", tem como objetivo de aplicação a conexão de todos os módulos de redes neurais implementados e também será convenientemente abordado.

\section{O USO DE RNAS}

Dentre as possíveis aplicações de RNAs, destacamos o seu emprego como reconhecimento de padrões que, em termos gerais, é a ciência que compreende a identificação e classificação da informação em categorias.

Uma RNA compreende um conjunto de elementos de processamento conectados e organizados em camadas. Um dos modelos de RNAs (feedforward) é disposto em camadas, onde as unidades são ordenadas e classificadas pela sua topologia e a propagação natural da informação é da camada de entrada para a de saída, sem realimentação para as unidades anteriores.

A mudança de valores das conexões entre os elementos de processamento, pesos e bias, envolve o processo de aprendizagem onde se utiliza de algoritmos de treinamentos que podem ser supervisionados, nãosupervisionados ou uma combinação destes. O algoritmo supervisionado apresenta como principal característica o prévio conhecimento da informação sobre as classes a que pertence cada um dos padrões na fase de treinamento. Um dos algoritmos de treinamento supervisionado mais utilizado é conhecido como backpropagation, ou de retropropagação, e pode ser aplicado a redes neurais feedforward com no mínimo uma camada intermediária. O algoritmo busca minimizar o erro entre uma saída obtida pela rede e uma saída desejada e, para tal, usa o método do gradiente descendente. Os erros determinados para as unidades da camada de saída e camadas intermediárias são então usados para reajustar os valores dos pesos e bias de cada unidade, respeitando a topologia da rede em análise.

Para a aplicação de RNAs ao problema de reconhecimento de padrões, relacionado à detecção, classificação e localização de faltas em linhas de transmissão, é indispensável a elaboração de um conjunto de padrões que represente as situações de falta do sistema elétrico analisado, neste caso designado por conjunto de dados. Este conjunto de padrões pode ser utilizado para o treinamento supervisionado de RNAs. Salienta-se que a formação deste conjunto deve, da melhor maneira possível, apresentar à rede neural as possíveis situações que a mesma possa encontrar, ou seja, situações representativas que definam claramente os tipos de falta que o sistema em questão está sujeito.

Outro aspecto importante para a análise das principais características inerentes a RNAs é a elaboração de um segundo conjunto de padrões, caracterizando um conjunto de testes a ser aplicado sobre a arquitetura de RNA após a fase de treinamento. Sendo estas situações de faltas pertencentes ao conjunto de testes diferentes das situações utilizadas na fase de treinamento, será possível verificar a capacidade de generalização e adaptação da RNA às operações do sistema elétrico.

Uma vez completo o treinamento, a rede neural deverá ser capaz de fornecer as saídas desejadas não somente para entradas conhecidas, mas também a resposta mais plausível para qualquer entrada relacionada aos padrões treinados.

Como destacado, o software NeuralWorks foi empregado com o objetivo de se obter as matrizes de pesos fixas que caracterizem as condições de operações sobre o sistema de transmissão. Utilizou-se do algoritmo supervisionado "Norm-Cum-Delta Learning Rule", uma variação do algoritmo De retropropagação, o qual é imune às alterações do tamanho da época (número de padrões aleatórios pertencentes ao conjunto de treinamento apresentados à arquitetura a cada iteração).

Como uma alternativa para a função de transferência sigmoidal, a função de transferência tangente hiperbólica foi utilizada. Durante a fase de treinamento, utilizaram-se valores de taxas de aprendizagem distintas para as unidades da camada intermediária e de saída compreendidas entre 0,4 a 0,01 , com valores de momento situados entre 0,2 e 0,001. Todo o trabalho foi executado sobre um Pentium II - $333 \mathrm{MHz}$. 


\section{UMA VISÃO GERAL DO ESQUEMA}

Devido às inúmeras situações aleatórias de faltas no sistema elétrico, o desempenho das redes neurais implementadas depende muito da escolha de um conjunto representativo de treinamento e teste. Por meio de simulações busca-se uma aproximação às situações e características encontradas na prática. Com o uso de ferramentas destinadas às simulações, viabiliza-se então, a obtenção de dados próximos aos reais, já que estes, por condições técnicas ou financeiras, não são disponíveis de imediato.

A topologia do sistema elétrico analisado em todo o trabalho é a representada na Figura 1. Nas simulações, consideram-se também as características dos condutores e suas respectivas disposições geométricas nas torres de transmissão. A estrutura da linha de transmissão de $440 \mathrm{kV}$ corresponde a uma linha típica da CESP (Companhia Energética de São Paulo), empregada entre as cidades de Araraquara - Bauru e Jupiá - Ilha Solteira.

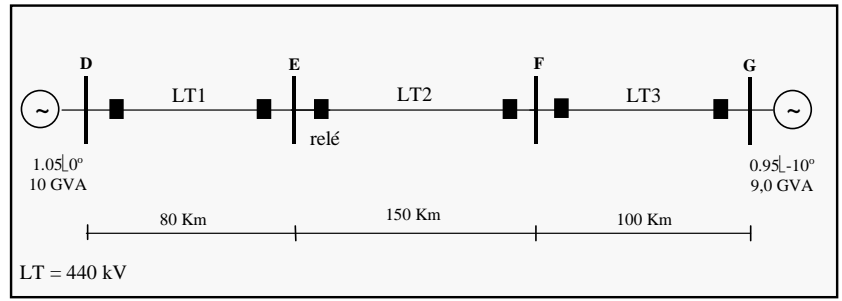

Figura 1: Sistema de energia analisado

Todas as simulações foram realizadas sobre o sistema de transmissão tendo como variáveis:

- a distância em quilômetros de aplicação da falta, em relação ao barramento E;

- a resistência de falta entre fases e fase a terra;

- o ângulo de incidência da falta;

- o tipo de falta considerada e

- a condição de operação do sistema elétrico.

Deve ser mencionado que, embora a técnica descrita é baseada em simulações computacionais, considerações práticas como o transformador de potencial capacitivo, amostragem do sinal (freqüência de $1 \mathrm{kHz}$ ), filtro antialiasing (freqüência de corte de $300 \mathrm{~Hz}$ ) e erros de quantização da conversão analógica/digital, também foram incluídos. A técnica também considera o arranjo físico e características dos condutores, acoplamento mútuo e linhas transpostas.
A obtenção e aplicação dos dados segue conforme apresentado na Figura 2. Nesta seqüência de operações, a inclusão do filtro anti-aliasing no sistema ilustrado, tem como objetivo reduzir os componentes harmônicos de alta freqüência do sinal amostrado com freqüências superiores a $300 \mathrm{~Hz}$, evitando-se a sobreposição de espectros (efeito aliasing), conforme apresentado por Phadke \& Thorp (1988). Conforme ilustra a Figura 2, faz parte do processamento dos dados uma conversão dos valores de tensões e correntes analógicos para os seus respectivos valores digitais. Neste estudo, empregou-se uma aproximação ao Conversor Analógico/Digital de 12 Bits, incluindo aos valores analisados de tensões e correntes os erros ou ruídos provenientes do processo. O processo de treinamento e testes das redes, bem como o algoritmo computacional final de proteção baseado em RNAs são também ilustrados na referida figura.

Como apresentado anteriormente, o desenvolvimento do trabalho está dividido em módulos, que dizem respeito à implementação das arquiteturas de redes neurais para a detecção, classificação e localização da falta com a conseqüente atuação do sistema de proteção, se necessária.

Na Figura 3, apresenta-se um modelo alternativo para a proteção no que diz respeito à aplicação de RNAs, o qual é o objetivo do trabalho. Para a Rede Neural Artificial 1 (RNA1), referente à detecção da falta, os valores trifásicos das tensões e correntes amostrados a uma freqüência de $1 \mathrm{kHz}$, considerando-se amostras de pré e pós-falta foram utilizados para treinar e testar a arquitetura.

Observa-se pelos resultados encontrados que, para a grande maioria das situações, com no máximo até três amostras pós-falta (3 ms), a rede é capaz de distinguir entre uma situação de falta à frente ou reversa a um determinado ponto do sistema, ou ainda, se for o caso, acusar uma condição normal de operação. Com a confirmação de uma situação de falta em sentido reverso ou à frente do ponto escolhido, o módulo de classificação (RNA2) atua distinguindo as fases envolvidas entre os dez (10) tipos de faltas (dispondo-se de 4 a 9 ms após a ocorrência do surto). Resta agora determinar as zonas de atuação dos relés de distâncias (a partir de 9 ms após a ocorrência da falta), para a conseqüente operação do sistema de proteção, as quais são indicadas pelas redes RNA3, RNA4 e RNA5. 


\section{O PROCESSO DE TREINAMENTO}

\subsection{A detecção da falta}

O objetivo deste módulo de detecção é reconhecer entre situações de faltas ocorrendo em sentido reverso a determinado ponto do sistema elétrico (barramento E) ou faltas ocorrendo à frente deste mesmo ponto, bem como reconhecer ainda as situações normais de operação, como descrito anteriormente.

Para formar um conjunto de dados representativo, 37 posições sobre o sistema foram escolhidas como pontos de aplicação das situações de faltas. Pela combinação destas posições com as variações dos três ângulos de incidência da falta $\left(0^{\circ}, 45^{\circ} \mathrm{e} 90^{\circ}\right)$ e as três resistências de faltas entre fase-terra $(0,50$ e $100 \Omega)$ ou com as três resistências de faltas entre fase-fase $(0,0,5$ e $1,0 \Omega)$ utilizadas, resultou um número de 333 situações para cada tipo de falta. Para caracterizar as condições normais de operação, foram incluídos no conjunto de dados 2016 padrões descrevendo as características normais do sistema.

Três janelas de dados com quatro amostras cada uma foram consideradas, dispondo-se de até $3 \mathrm{~ms}$ após a ocorrência da situação de falta.

Sendo assim, o conjunto de dados é formado por 12006 padrões (37 localizações da falta x 3 resistências de falta x 3 ângulos de incidência da falta x 3 janelas de dados = 999 situações por tipo de falta, 999 situações x 10 tipos de faltas $=9990$ padrões, $9990+2016$ padrões representando as condições normais de operação $=12006$ padrões).

Para cada módulo (detecção, classificação e localização), o conjunto de dados é subdividido em um conjunto de treinamento e em um conjunto de validação. Este último é usado para avaliar a RNA durante a fase de treinamento. Este procedimento é necessário para se evitar o sobre treinamento da RNA. Nesta situação, o processo de treinamento deve ser interrompido quando se alcançar o menor erro quadrático médio, ou RMS (do inglês Root Mean Square Error), para o conjunto de validação ainda na fase de treinamento. O tamanho do conjunto de treinamento e de validação corresponde a $80 \%$ e $20 \%$ de todos os exemplos do conjunto de dados respectivamente. Nos conjuntos de treinamento e validação utilizados, as condições de faltas apresentadas às RNAs foram dispostas no arquivo de maneira aleatória.

Cabe agora exemplificar a utilização das três janelas de dados empregadas. Designando F como sendo o instante de aplicação da falta, a primeira janela de dados contém os quatro valores amostrados das tensões nas fases $\mathrm{A}$, $\mathrm{B}$ e C $\left(\mathrm{VA}_{F-2}, \mathrm{VA}_{F-1}, \mathrm{VA}_{F}, \mathrm{VA}_{F+1}, \mathrm{VB}_{F-2}, \mathrm{VB}_{F-1}\right.$,

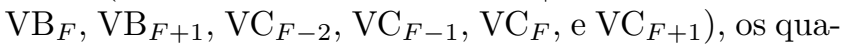
tro valores amostrados das correntes $\left(\mathrm{IA}_{F-2}, \mathrm{IA}_{F-1}\right.$, $\mathrm{IA}_{F}, \mathrm{IA}_{F+1}, \mathrm{IB}_{F-2}, \mathrm{IB}_{F-1}, \mathrm{IB}_{F}, \mathrm{IB}_{F+1}, \mathrm{IC}_{F-2}, \mathrm{IC}_{F-1}$, $\mathrm{IC}_{F}$, e $\mathrm{IC}_{F+1}$ ), adicionando-se ainda a mesma janela, as duas respostas esperadas da RNA para a situação de falta apresentada $\left(D_{1}\right.$ e $\left.D_{2}\right)$ que serão explicadas ainda neste item.

Para a segunda janela de dados, deslocando-se $1 \mathrm{~ms}$ nas formas de ondas dos sinais avaliados, a mesma apresentará dois valores amostrados de pré e dois valores amostrados de pós-falta dos sinais de tensões e correntes, bem como as respostas esperadas para tal situação.

Já para a terceira janela de dados, a mesma conterá 1 valor amostrado de pré e três valores amostrados dos sinais de pós-falta, somando-se ainda as duas respostas esperadas.

Na Tabela 1 ilustram-se as duas respostas esperadas por parte da RNA1. Nesta, se os padrões apresentados a RNA1, seja na fase de treinamento ou durante a fase de teste, descreverem uma situação normal do sistema, a resposta deverá ser um valor próximo ou igual a 0 (zero) para as duas saídas $\left(\mathrm{D}_{1}\right.$ e $\left.\mathrm{D}_{2}\right)$. Encontram-se também ilustradas na tabela, as respostas esperadas se situações de faltas reversas ou à frente forem observadas.

Para todos os módulos representados por RNAs, convencionou-se que as saídas $\left(\mathrm{S}_{i}\right)$ observadas no intervalo de 0 a $0,3\left(0 \leq S_{i} \leq 0,3\right)$ indicariam uma resposta igual a 0 (zero) e que valores situados entre o intervalo de 0,7 a $1,0\left(0,7 \leq \mathrm{S}_{i} \leq 1,0\right)$, respostas iguais a 1 (um). Os demais valores indicariam uma indecisão por parte das arquiteturas de RNAs. No algoritmo computacional implementado, se uma indecisão for apontada, espera-se as próximas respostas por parte das RNAs até se obter uma resposta estável, que venha a caracterizar a situação apresentada.

Neste módulo de detecção, várias arquiteturas de RNAs do tipo perceptron multi-camadas, ou MLP (do inglês Multi Layer Perceptron), foram avaliadas, variando-se, como por exemplo, o número de elementos de processamentos (neurônios) na camada intermediária, taxas de aprendizagem e de momento, número de ciclos de treinamento, número de padrões pertencentes ao conjunto de dados, número de janelas empregadas e demais parâmetros quando convenientes.

Índices aceitáveis foram observados com uma arquitetura que apresenta 24 unidades de processamento na sua camada de entrada, 9 unidades de processamen- 


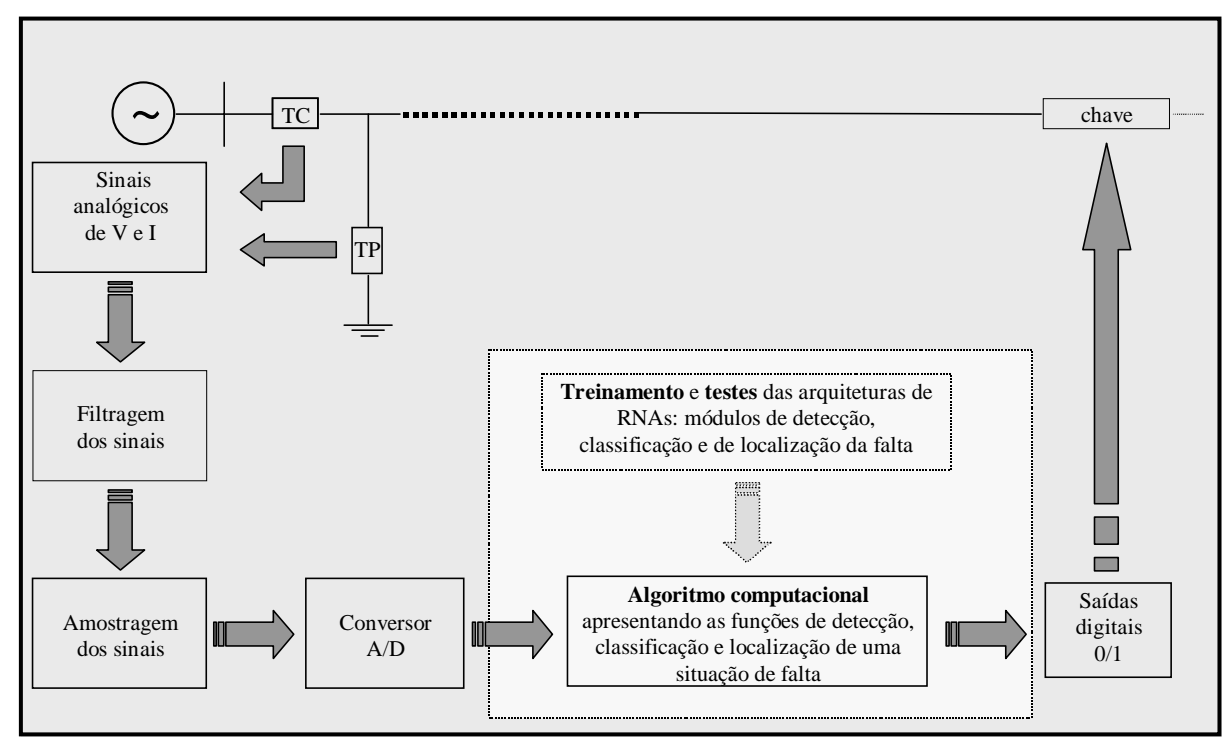

Figura 2: Obtenção e análise dos dados

to na camada intermediária e 2 elementos na camada de saída (arquitetura 24-9-2).

Dos apontamentos anteriores, relembra-se que a RNA1 foi treinada testando-se a mesma através de um conjunto de validação, cujo principal objetivo era de se evitar o sobre- treinamento. Assim, a arquitetura 24-9-2 alcançou um erro RMS mínimo para o conjunto de validação de 0,0569 para todas as unidades na camada de saída.

Conforme apresentado na Tabela 2, verifica-se que a arquitetura 24-9-2 foi capaz de reconhecer todos os padrões (índice de acerto de 100\%), classificando-os como condições normais de operação e situações de faltas reversas e ou à frente de determinada ponto. Tais resultados, bem como o conjunto de teste aplicado sobre a configuração, serão apresentados e discutidos posteriormente.

\subsection{A classificação da situação}

Para este módulo, as informações referentes às condições de operação do sistema são representadas através de 138 diferentes situações (localizações) para cada tipo de falta, combinando-as com as resistências (para faltas

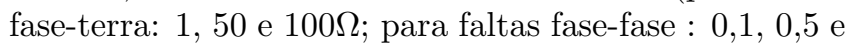
$1,0 \Omega)$ e com os ângulos de faltas aplicados $\left(0\right.$ e $\left.90^{\circ}\right)$. Um total de 1380 diferentes situações de faltas sobre sistema foram consideradas para formar o conjunto de dados.

Cinco janelas de dados com quatro amostras cada foram empregadas. Assim, o conjunto de dados é formado através de 6900 situações (1380 situações de faltas x 5 janelas de dados).

Fixaram-se as segundas amostras de tensões e correntes pós-faltas como sendo os valores iniciais a serem considerados na primeira janela de dados. A janela 1 contém quatro amostras das tensões pós-falta

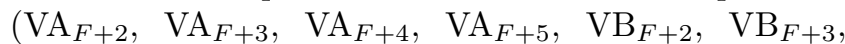
$\mathrm{VB}_{F+4}, \mathrm{VB}_{F+5}, \mathrm{VC}_{F+2}, \mathrm{VC}_{F+3}, \mathrm{VC}_{F+4}$ e $\mathrm{VC}_{F+5}$,). Também estão inclusas nesta janela as quatro amostras relativas às correntes pós-falta $\left(\mathrm{IA}_{F+2}, \mathrm{IA}_{F+3}, \mathrm{IA}_{F+4}\right.$, $\mathrm{IA}_{F+5}, \mathrm{IB}_{F+2}, \mathrm{IB}_{F+3}, \mathrm{IB}_{F+4}, \mathrm{IB}_{F+5}, \mathrm{IC}_{F+2}, \mathrm{IC}_{F+3}$, $\mathrm{IC}_{F+4}$ e $\mathrm{IC}_{F+5}$,) com a respectiva resposta esperada por parte da rede neural para uma situação de falta ao longo da linha transmissão $\left(\mathrm{C}_{1}, \mathrm{C}_{2}, \mathrm{C}_{3}\right.$ e $\left.\mathrm{C}_{4}\right)$. Para uma situação que caracterize uma falta fase $\mathbf{A}$ - terra, relacionam-se as respostas $\mathrm{C}_{1}=1, \mathrm{C}_{4}=1 \mathrm{com} \mathrm{C}_{2}$ e $\mathrm{C}_{3}$ $=0$ conforme pode ser observado na Tabela 1 .

A Tabela 1 mostra as respostas esperadas por parte da arquitetura de RNA2 relacionadas às fases $\mathrm{A}\left(\mathrm{C}_{1}\right), \mathrm{B}$ $\left(\mathrm{C}_{2}\right)$ e $\mathrm{C}\left(\mathrm{C}_{3}\right)$ e a conexão à terra $\left(\mathrm{C}_{4}\right)$ para todas a condições de faltas consideradas. Como resposta, a arquitetura de RNA2 implementada deve apresentar valores iguais ou próximos a um (1) ou zero (0), mostrando se a falta envolveu as fases $A\left(C_{1}\right), B\left(C_{2}\right)$ e $C\left(C_{3}\right)$ ou não. A saída $\left(\mathrm{C}_{4}\right)$ foi designada para indicar se a falta envolveu uma conexão à terra.

Diferentes topologias de redes neurais MLP foram avaliadas, buscando-se de maneira empírica a que melhor representasse o problema de classificação em questão. A arquitetura escolhida apresenta 
Tabela 1: Respostas esperadas por parte das RNAs

\begin{tabular}{|c|c|c|c|c|c|c|c|c|c|c|c|}
\hline \multicolumn{3}{|c|}{$\begin{array}{l}\text { MÓDULO DE } \\
\text { DETECÇÃA }\end{array}$} & \multicolumn{5}{|c|}{$\begin{array}{c}\text { MÓDULO DE CLASSIFICAÇÃO } \\
\text { RNA2 }(24-16-4)\end{array}$} & \multicolumn{4}{|c|}{$\begin{array}{l}\text { MÓDULO DE } \\
\text { LOCALIZAÇÃO }\end{array}$} \\
\hline Situação & $\overline{D_{1}}$ & $\overline{\mathrm{D}_{2}}$ & Tipo de falta & $\mathrm{C}_{1}$ & $\mathrm{C}_{2}$ & $\mathrm{C}_{3}$ & $\mathrm{C}_{4}$ & Localização da falta & $\mathrm{L}_{1}$ & $\mathrm{~L}_{2}$ & $\mathrm{~L}_{3}$ \\
\hline Normal & 0 & 0 & $\mathrm{~A}-\mathrm{E}$ & 1 & 0 & 0 & 1 & Zona 1 & 1 & 0 & 0 \\
\hline Falta reversa & 1 & 0 & $\mathrm{~B}-\mathrm{E}$ & 0 & 1 & 0 & 1 & Zona 2 & 0 & 1 & 0 \\
\hline Falta à frente & 0 & 1 & $\mathrm{C}-\mathrm{E}$ & 0 & 0 & 1 & 1 & Zona 3 & 0 & 0 & 1 \\
\hline \multirow{7}{*}{\multicolumn{3}{|c|}{ RNA1(24-9-2) }} & $\overline{\mathrm{AB}}$ & 1 & 1 & 0 & 0 & \multirow{7}{*}{\multicolumn{4}{|c|}{$\begin{array}{l}\text { RNA3 }(24-48-44-3) \\
\text { RNA4 }(24-42-40-3) \\
\text { RNA5 }(24-24-20-3)\end{array}$}} \\
\hline & & & $\overline{\mathrm{AC}}$ & 1 & 0 & 1 & 0 & & & & \\
\hline & & & $\mathrm{BC}$ & 0 & 1 & 1 & 0 & & & & \\
\hline & & & AB-E & 1 & 1 & 0 & 1 & & & & \\
\hline & & & AC-E & 1 & 0 & 1 & 1 & & & & \\
\hline & & & BC-E & 0 & 1 & 1 & 1 & & & & \\
\hline & & & $\mathrm{ABC}$ & 1 & 1 & 1 & 0 & & & & \\
\hline
\end{tabular}

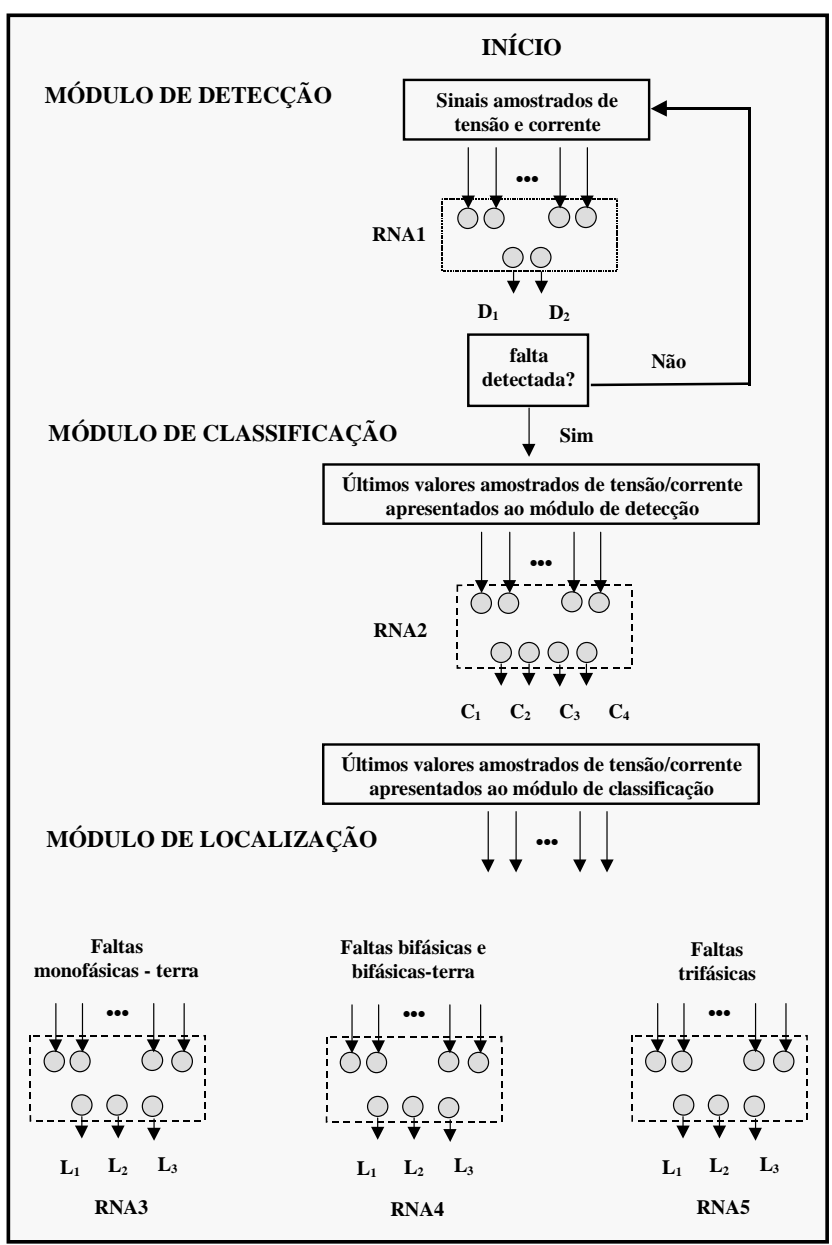

Figura 3: Modelo alternativo para a proteção aplicandose redes neurais artificiais
24 unidades de processamento na camada de entrada, 16 unidades na camada escondida e uma camada de saída com apenas 4 unidades de processamento (arquitetura 24-16-4).

O processo de treinamento alcançou um erro mínimo (RMS) de validação na ordem de 0,10 para todas as unidades na camada de saída.

A Tabela 2 mostra a percentagem de respostas corretas da arquitetura empregada sujeita ao conjunto de teste formado. Como pode ser observado, os resultados obtidos são altamente satisfatórios e serão comentados no item 5 .

\subsection{A localização do defeito}

Com a crescente disponibilidade dos circuitos integrados e uso de microprocessadores, observou-se a possibilidade da aplicação do processador digital para desempenhar as funções atribuídas ao modelo convencional do relé de distância. Contudo, a proteção digital de distância é usualmente definida sobre uma característica fixa de atuação do relé. As incertezas do alcance de sua zona de proteção são de 5\%, sendo usual a definição de sua zona de proteção primária como sendo 80-90\% do comprimento da linha de transmissão a ser protegida (Stanley \& Phadke, 1992).

Neste estudo em específico, tomando-se como referência o sistema elétrico apresentado na Figura 1, as zonas de proteção foram designadas com as seguintes proporções:

a) Zona de proteção primária: até $142,5 \mathrm{~km}$ a partir do barramento E, o que corresponde a 95\% da LT2 de $150 \mathrm{~km}$;

b) Primeira zona de transição: $142,5 \pm 2,85 \mathrm{~km}$ a partir 
do barramento E o que corresponde a um índice de incerteza de $\pm 2 \%$ sobre os $142,5 \mathrm{~km}$ considerados para a zona de proteção primária;

c) Zona de proteção secundária: até $195 \mathrm{~km}$ a partir do barramento E, o que corresponde a $130 \%$ da LT2 de $150 \mathrm{~km}$;

d) Segunda zona de transição: $195 \pm 3,9 \mathrm{~km}$ a partir do barramento $\mathrm{E}( \pm 2 \%$ de $195 \mathrm{~km})$ e

e) Zona de proteção terciária: até $240 \mathrm{~km}$ a partir do barramento E o que corresponde a $150 \%$ da LT2 de $150 \mathrm{~km}$.

As duas zonas de transição mencionadas (primeira e segunda) resultam do fato da alteração dos valores próximos ou iguais a 0 (zero) para valores próximos ou iguais a 1 (um), ou vice-versa, que devem ser apresentados pela RNA quando da mudança entre as zonas de proteção. $\mathrm{O}$ que caracteriza esta transição à rede é a passagem pelo ponto (distância) de $142,5 \mathrm{~km}$ para a zona de proteção primária e o ponto (distância) de $195 \mathrm{~km}$ para a zona de proteção secundária, ambas tomadas com relação ao barramento E. Assim sendo, como há a alteração entre os valores esperados como respostas, há uma pequena área de transição para a rede onde valores ou localizações errôneas são esperadas. Esta área para a zona de proteção primária está definida como $\pm 2 \%$ de $142,5 \mathrm{~km}$ (variando de $139,65 \mathrm{~km}$ a $145,35 \mathrm{~km}$ ) e para a zona de proteção secundária variando de 191,1 a 198,9 km ( \pm $2 \%$ de $195 \mathrm{~km})$.

Para a implementação do módulo de localização, três RNAs foram treinadas e implementadas (Figura 3). As três RNAs referem-se aos três agrupamentos a que foram alocados os diversos tipos de falta. A RNA3 designa-se a localizar as faltas do tipo fase-terra (A-terra, B-terra e C-terra) sobre o sistema elétrico em questão. O segundo grupo refere-se às faltas do tipo fase-fase $(\mathrm{AB}, \mathrm{AC} \mathrm{e}$ $\mathrm{BC}$ ) e fase-fase-terra (AB-terra, AC-terra e BC-terra), sendo a RNA4 elaborada para tal objetivo. O terceiro grupo refere-se às faltas trifásicas (fases $\mathrm{ABC}$ ) e está representado pela RNA5.

\subsubsection{Faltas fase-terra}

Como apontado anteriormente, para esta rede (RNA3) designa-se a localização de situações de faltas envolvendo uma fase a terra sobre o sistema. Sendo assim, a rede neural associada apresenta três unidades de processamento em sua camada de saída, cada uma sendo responsável por uma área de localização. A saída $\mathrm{L}_{1}$ relaciona-se à zona de proteção primária e as saídas $\mathrm{L}_{2}$ e $\mathrm{L}_{3}$ as zonas de proteções secundária e terciária respectivamente. Esta mesma associação às zonas de proteção também será mantida para as demais redes que compõem este módulo (RNA4 e RNA5). Neste módulo, saídas com valores próximos ou iguais a 0 (zero) indicam o não envolvimento da área de proteção e saídas com valores iguais ou próximos a 1 (um) o envolvimento, ou seja, a ocorrência de uma situação de falta na zona de proteção indicada. Os valores intermediários a 0,3 e 0,7 indicam a indecisão da rede em localizar a situação de falta apresentada. As respostas esperadas por parte da rede neural estão ilustradas na Tabela 1. Para as demais redes que compreendem o módulo de localização (para faltas fase-fase, fase-fase-terra e faltas trifásicas) esta tabela também será válida, conforme é evidenciado.

Para formular o conjunto de dados utilizados para o treinamento da arquitetura, fez-se a combinação dos parâmetros já mencionados. Estes parâmetros referem-se às localizações $(\mathrm{km})$ das situações de faltas simuladas (49 posições) com relação ao barramento $\mathrm{E}$, os cinco valores de resistências de faltas fase - terra empregados (1, 25,50 e $100 \Omega$ ) bem como, os cinco valores de ângulos de incidência da falta adotados para este tópico $(0,30$, 45,60 e $90^{\circ}$ ). Da combinação destas variáveis resultam 1225 diferentes situações para cada tipo de falta considerada. O conjunto de treinamento corresponde a $80 \%$ dos 14700 padrões que compõem o conjunto de dados (80\% de 1225 situações x 3 tipos de faltas x 4 janelas de dados) e o conjunto de validação a $20 \%$ do mesmo $(20 \%$ de 14700 padrões).

Ao total foram avaliadas (treinadas) 63 arquiteturas MLP, variando-se todos os possíveis parâmetros da rede, desde número de camadas intermediárias, número de elementos em cada camada, taxas de aprendizagem, conjunto de dados e ordem da apresentação dos valores amostrados na camada de entrada.

A arquitetura de RNA escolhida, apresenta 24 unidades na camada de entrada, intermediárias com 48 e 44 unidades cada e uma camada de saída com 3 unidades. A arquitetura 24-4844-3 encontrada atende aos três possíveis tipos de faltas fase-terra (fase A-terra, B-terra e C-terra). No entanto, tanto para o processo de treinamento quanto para o de teste, os valores amostrados das fases foram invertidos quando da apresentação para a rede conforme é apresentado no que segue. Para as faltas entre a fase A com conexão à terra os dados apresentados à RNA3 foram dispostos respeitando a ordem natural das fases (A, B e C) tanto para os valores amostrados de tensão como para os de corrente. Para as faltas entre a fase B com conexão à terra a ordem respeitada foi $\mathrm{B}, \mathrm{A}$ e $\mathrm{C}$ 
Tabela 2: Respostas corretas e tempo de processamento para os módulos de detecção, classificação e localização integrados.

\begin{tabular}{|c|c|c|c|c|c|}
\hline \multicolumn{6}{|c|}{$\begin{array}{l}\text { Percentagem (\%) de Respostas Corretas (R.C.) } \\
\text { e o Tempo de Processamento (T.P.) para cada módulo }\end{array}$} \\
\hline MÓDULO & $\begin{array}{l}\text { T.P. } \\
(\mathrm{ms})\end{array}$ & $\begin{array}{c}\text { Faltas } \\
\text { fase - terra }\end{array}$ & $\begin{array}{c}\text { Faltas } \\
\text { fase - fase }\end{array}$ & $\begin{array}{c}\text { Faltas } \\
\text { fase - fase - terra }\end{array}$ & $\begin{array}{l}\text { Faltas } \\
\text { trifásicas }\end{array}$ \\
\hline \multirow{4}{*}{ Detecção 4050 padrões testados } & R.C. & 100 & 100 & 100 & 100 \\
\hline & 2 & 71,94 & $\overline{76,46}$ & 82,14 & 84,44 \\
\hline & 3 & 23,29 & 22,63 & 16,79 & 15,56 \\
\hline & $4-5$ & 4,77 & 0,91 & 1,07 & - \\
\hline \multirow{8}{*}{ Classificação 4050 padrões testados } & R.C. & 99,92 & 100 & 99,26 & 99,52 \\
\hline & 4 & 24,20 & - & - & - \\
\hline & 5 & $\begin{array}{l}37,94 \\
\end{array}$ & 4,44 & 6,18 & - \\
\hline & 6 & 31,36 & 21,89 & 12,92 & - \\
\hline & 7 & 5,60 & 17,12 & 31,28 & 30,37 \\
\hline & 8 & 0,58 & 31,93 & 35,48 & 26,91 \\
\hline & 9 & 0,24 & 13,58 & 10,54 & 24,70 \\
\hline & $10-17$ & - & 11,04 & 2,86 & 17,54 \\
\hline \multirow{10}{*}{ Localização 3240 padrões testados } & R.C. & 94,65 & 88,78 & 95,97 & 92,84 \\
\hline & 8 & 0,61 & - & 0,31 & - \\
\hline & 9 & 4,12 & 2,06 & 6,50 & - \\
\hline & 10 & 14,10 & 6,38 & 15,53 & 5,03 \\
\hline & 11 & 19,60 & 22,02 & 27,01 & 17,61 \\
\hline & 12 & 21,13 & 18,11 & 23,46 & 21,07 \\
\hline & 13 & $\begin{array}{l}17,39 \\
\end{array}$ & 20,06 & $\begin{array}{l}13,89 \\
\end{array}$ & 28,63 \\
\hline & 14 & 12,34 & 8,54 & 5,02 & $\overline{13,59}$ \\
\hline & 15 & 4,42 & 7,41 & 2,76 & 3,72 \\
\hline & $16-18$ & 0,94 & 4,20 & 1,49 & 3,19 \\
\hline
\end{tabular}

para todas as amostras consideradas. Já para as faltas entre a fase $\mathrm{C}$ com conexão à terra os valores foram dispostos respeitando a seqüência C, B e A.

Sendo que estas inversões entre as fases não acarretam um considerável atraso no processamento do sinal, após a classificação do tipo de falta ocorrido, os sinais podem ser direcionados para os módulos de localização fazendo-se as adaptações necessárias. Esta mesma ordem de apresentação dos dados é mantida quando da implementação do algoritmo computacional.

Seguindo a ordem descrita de apresentação dos valores amostrados, a arquitetura 24-48-44-3 apresentou um erro mínimo (RMS) aproximado de 0,08 para o conjunto de validação.

\subsubsection{Faltas entre duas fases com e sem conexão à terra}

A arquitetura treinada e escolhida dentre várias tentativas apresenta as suas 24 unidades de processamento da camada de entrada conectadas as suas duas camadas in- termediárias com 42 e 40 unidades de processamento e a sua camada de saída com 3 unidades de processamento (arquitetura 24-42-40-3). O conjunto de treinamento foi formulado pela combinação das variáveis anteriormente citadas. O processo de treinamento seguiu como para as demais redes já apresentadas. As situações de faltas entre duas fases sem conexão à terra foram representadas por 9225 padrões (41 localizações sobre o sistema x 5 valores de resistências de faltas entre fases x 3 ângulos de incidência de falta $\times 3$ tipos de faltas $\times 5$ janelas de dados). Já as situações de faltas que envolvem duas fases com conexão à terra, 22575 padrões foram empregados (43 localizações sobre o sistema x 5 valores de resistências de faltas fase-terra $\mathrm{x} 5$ ângulos de incidência de falta $\mathrm{x} 3$ tipos de faltas $\mathrm{x} 7$ janelas de dados) totalizando um conjunto de dados de 31800 padrões. Relembra-se que deste número, $80 \%$ foram empregados para formar o conjunto de treinamento (25440) e o restante para compor o conjunto de validação.

O erro mínimo (RMS) para todas as unidades na camada de saída referentes ao conjunto de validação foi da ordem de 0,15 para os $6360 \overline{\text { padrões apresentados }}(1845$ 
padrões referentes as situações entre duas fases com conexão à terra e 4515 referentes as outras situações).

Para as faltas entre as fases A e B com e sem conexão à terra os dados apresentados à RNA4 foram dispostos respeitando a ordem natural das fases (A, B e C) tanto para os valores amostrados de tensão como para os de corrente. Para as faltas entre a fases A e C com e sem conexão à terra a ordem respeitada foi $\mathrm{A}, \mathrm{C}$ e $\mathrm{B}$ para todas as amostras consideradas. Já para as faltas entre as fases $\mathrm{B}$ e $\mathrm{C}$ com e sem conexão à terra os valores foram dispostos respeitando a seqüência B, C e A.

\subsubsection{Faltas trifásicas}

Com respeito à localização de faltas trifásicas, poucas alterações foram efetuadas comparando-se aos itens anteriores (4.3.1 e 4.3.2). Para alcançar a arquitetura de RNA desejada, basicamente a disposição dos sinais de entrada à rede diverge das anteriores, pois neste caso, não houve a necessidade da inversão entre as fases. As 24 unidades de processamento da camada de entrada recebem os três valores trifásicos amostrados dos sinais de tensão (fases A, B e C) e os três valores trifásicos amostrados de corrente nas respectivas fases.

Quatro janelas de dados contendo 4 amostras de cada sinal analisado (tensões e correntes trifásicas) foram empregadas no processo de treinamento. O conjunto de dados foi formado por 1525 situações de faltas decorrentes da combinação entre a localização de aplicação da falta (61 posições), as resistências de falta (5 valores) e os ângulos de incepção da falta (5 valores). Assim, considerando-se as 4 janelas de dados, o conjunto final apresenta 6100 padrões. Destes padrões, $80 \%$ foram empregados para formar o conjunto de treinamento (4880 padrões) e $20 \%$ designados para compor o conjunto de validação (1220 padrões). Como em todos os conjuntos empregados no trabalho, os padrões foram dispostos de maneira aleatória quando do processo de treinamento da RNA.

Na busca de uma arquitetura, várias topologias de redes neurais MLPs também foram avaliadas, com o intuito de se encontrar uma que melhor atendesse em resposta à localização das situações de faltas apresentadas. Ao total, 25 arquiteturas foram analisadas variando-se parâmetros como: números de elementos de processamento nas diversas camadas, conjuntos de treinamento, taxas de aprendizagem, etc. A arquitetura escolhida apresenta 24 unidades de processamento na camada de entrada

e 3 unidades de processamento na camada de saída (como em todas as demais já apresentadas). Para as duas camadas intermediárias, foram alocadas
24 unidades de processamento (primeira camada intermediária) e 20 unidades de processamento para a segunda camada intermediária (arquitetura 24-24-20-3). Quando da apresentação à rede do conjunto de validação, a arquitetura apresentou um erro mínimo total (RMS) de 0,04 para todas as unidades na camada de saída.

Cabe ressaltar que o processo de treinamento para as arquiteturas utilizadas nós vários módulos apresentados é um dos principais pontos a ser analisado e discutido, visando uma aplicação prática. Apenas ilustrando, para as redes neurais empregadas para o módulo de localização, sem considerar o conjunto de validação aplicado, o tempo disposto para o processo varia entre 12 a 14 h, executado em um microcomputador Pentium II, 333 $\mathrm{MHz}$. O tempo despendido para o processo de treinamento é, em grande parte, dependente do método do gradiente descendente que apresenta por si só, uma convergência lenta e merece especial atenção na definição dos seu principais parâmetros.

\section{TESTES REALIZADOS}

Pelo que foi apresentado e observado nas implementações dos módulos anteriores - detecção, classificação e localização, nota-se que as redes neurais empregadas convergiram rapidamente para uma resposta esperada. No entanto, tomando-se como exemplo um conjunto de cinco respostas do módulo de classificação, muitas das vezes estas respostas divergem em um número de classificações corretas e errôneas. Tendo este fato em análise, procurou-se então melhorar a tomada de decisão frente aos módulos implementados, optando-se em não analisar unicamente uma resposta da rede neural e sim, o conjunto das respostas pertinentes a cada módulo de detecção, classificação e de localização.

Para o módulo de detecção, verifica-se que são necessários $3 \mathrm{~ms}$ pós-falta para a tomada de decisão e, consequentemente, as respostas das três janelas de dados serão analisadas. Já para o módulo de classificação o número de janelas de dados necessárias varia de três a cinco, o mesmo ocorrendo para o módulo de localização. Claro que este número de respostas/janelas consideradas em cada módulo vem e muito a influenciar no desempenho do sistema como um todo. Sendo assim, no que segue, será apresentada a lógica do algoritmo computacional implementado, tomando-se como base para a análise, o número de respostas corretas ou não, apresentadas por cada módulo.

Como anteriormente evidenciado, o algoritmo computacional implementado em linguagem de programação "C", 
obedece a uma forma seqüencial de ativação dos módulos considerados. Sendo assim, para uma fase de teste do mesmo, 4050 novos casos de prováveis situações que possam a vir ocorrer sobre o sistema de transmissão em análise foram simulados e apresentados, caso a caso, ao algoritmo em fase de experimento.

O conjunto de teste formulado compreende 405 diferentes casos para cada tipo de falta considerada. As situações de faltas analisadas são compostas pela combinação das seguintes variáveis:

- Localização da falta (km) - 6, 10, 15, 30, 45, 60, 65, $70,74,88,105,115,125,135,145,155,165,175$, 185, 195, 202, 208, 212, 218, 222, 223, 225, 238, $243,248,253,258,263,268,273,278,282,288$, $293,298,302,308,313,318$, e 320 ;

- Resistência de falta $(\Omega)$ - fase - terra: 30, 60, 90 e fase - fase: $0,3,0,6$, e 0,9 ;

- Ângulo de incidência da falta $\left(^{\circ}\right)$ - 20, 50, e 80.

Como no processo de treinamento, quatro amostras dos valores de tensões e correntes trifásicos (valores de pré e de pós-falta), amostrados a uma freqüência de $1 \mathrm{kHz}$, foram dispostos como valores de entrada.

Apresentando-se as situações simuladas caso a caso, as respostas por parte do algoritmo computacional foram registradas a medida que cada módulo implementado era ativado e desativado, passando os sinais amostrados em análise para o módulo seguinte.

A Tabela 2 apresenta em síntese todos os resultados registrados, onde o Tempo de Processamento (T.P.), em destaque, provém basicamente da soma dos intervalos de tempo entre cada valor amostrado do sinal considerado (1 ms) A percentagem de Respostas Corretas (R.C.) também está evidenciada, sendo que, para os módulos de deteç̧ão e de classificação, observam-se índices muito próximos a 100\%. Apenas esclarecendo como estes índices foram registrados, dos casos representativos de situações de faltas que envolvam uma fase com conexão à terra ( $\mathrm{A}$ - terra, $\mathrm{B}$ - terra e $\mathrm{C}$ - terra), 71,94\% dos casos foram detectados dispondo-se de $2 \mathrm{~ms}$ pós-falta. $23,29 \%$ foram corretamente detectados considerando-se até $3 \mathrm{~ms}$ e $4,77 \%$ tomando-se um tempo de 4 a $5 \mathrm{~ms}$ pós-falta. Destaca-se que, mesmo para as situações detectadas em um tempo maior do que $3 \mathrm{~ms}$ os demais módulos, ainda assim, apresentaram respostas corretas às suas funções.

Relembrando da filosofia adotada para as zonas de proteção, temos definido sobre o sistema de transmissão duas áreas de transição onde valores incorretos na localização da falta são esperados. Conforme apresentado, estas áreas de incertezas correspondem a um índice de $\pm 2 \%$ sobre o comprimento considerado e já foram definidas anteriormente. Este fato contudo vem e muito a esclarecer os índices apresentados pelo módulo de localização, já que, a grande maioria das respostas incorretas deste módulo recaem sobre estas supostas áreas de transição. Como exemplo, afirmamos que aproximadamente $5 \%$ dos erros ocorridos na localização de situações de faltas que envolvam duas fases sem conexão à terra recaem nas duas áreas de transição anteriormente definidas. Com isto, o índice geral de acertos para estas situações passa de $88,78 \%$ para $93,78 \%$. Este último índice é encontrado considerando-se somente o número de respostas corretas apresentadas pelo módulo referentes às zonas de proteção primária, secundária e terciária.

Vale ressaltar que este modelo proposto está atuando como um identificador direcional de faltas, um classificador de faltas (sejam as situações de faltas em sentido reverso ou à frente de um determinado ponto) e ainda como um localizador da mesma.

\section{CONCLUSÕES}

O uso de arquiteturas de RNAs como modelos alternativos para a detecção, classificação e localização de faltas em linhas de transmissão foram investigadas nesta pesquisa. Os modelos utilizam os valores de pré e de pós-falta das tensões e correntes trifásicas apresentados através de janelas de dados. Para este estudo são consideradas faltas fase-terra, fase-fase, fase-fase-terra e faltas trifásicas.

Os resultados obtidos mostram que o desempenho global das arquiteturas de redes neurais implementadas alcançou um índice altamente satisfatório no que diz respeito à precisão e velocidade das respostas para todos os módulos descritos.

Referindo-se aos casos testados para o módulo de detecção, as saídas da rede neural designadas a esta função convergiram rapidamente, para a grande maioria dos casos, a níveis corretos dispondo-se de até $3 \mathrm{~ms}$ após a ocorrência da falta. Além de monitorar as condições normais de operação do sistema, este módulo também trabalha como um discriminador direcional, reconhecendo entre situações de faltas à frente ou em sentido reverso de um determinado ponto sobre o sistema.

Com respeito ao módulo de classificação, este foi capaz de corretamente discriminar as fases envolvidas nas situações de faltas apresentadas, em um tempo situado 
entre 4 e 9 ms após a ocorrência da falta.

Finalmente, considerando as três zonas de proteção e todos os tipos de faltas citados, os resultados claramente mostram que esta aproximação conduz a níveis aceitáveis para a função de localizar a situação de falta sobre o sistema, com tempo situado entre 8 a $15 \mathrm{~ms}$ após a ocorrência da mesma.

Deve ser destacado que para o modelo de relé de distância implementado pelo emprego de RNAs, o mesmo estimou corretamente $98 \%$ das respostas esperadas por parte de um sistema de proteção. Índice este, alcançado considerando-se 4050 novos casos que descrevem algumas das condições operacionais que o sistema venha a encontrar. O número total de erros observados corresponde a $2 \%$ e está, em sua maioria, situado sobre as zonas de transições definidas para o modelo.

Deve ser enfatizado que uma extensão da zona de proteção primária foi alcançada para um valor de 95\% do comprimento da linha analisada. Tal acréscimo desta zona de proteção vem a melhorar a confiabilidade e o desempenho do sistema de proteção como um todo.

O esquema proposto se mostra altamente preciso com alta velocidade de atuação, apresentando características bastante desejáveis em um sistema de proteção moderno.

\section{AGRADECIMENTOS}

Os autores gostariam de agradecer aos Departamentos de Engenharia Elétrica e Eletrônica da Universidade de Bath (Inglaterra) e da Escola de Engenharia de São Carlos/USP (Brasil) pelas facilidades proporcionadas quando do desenvolvimento deste trabalho, bem como ao apoio financeiro recebido por parte da FAPESP - Fundação de Amparo à Pesquisa do Estado de São Paulo. Além destes, os nossos agradecimentos à empresa NeuralWare - Aspen Technology da qual provém o software NeuralWorks empregado neste trabalho.

\section{REFERÊNCIAS}

Aggarwal R. K., Xuan Q. Y., Johns A. T. and Bennett A. (1999). "Fault classification technique for double-circuit lines based on a combined unsupervised/supervised neural network". IEEE Transactions on Power Delivery, Vol. 14, No. 4, pp. 12501256.

Al-Hasawi, W. M.; Abbasy, N. H. and Mansour, M. (1997). Using fault induced transients and neural networks for T. L. ultra high-speed fault de- tection and classification. IPST'97 - International Conference on Power Systems Transients, Seattle, pp.412-417.

ALTERNATIVE Transients Program (1987). Rule Book, Leuven EMTP Center (LEC).

Chakravarthy, S. K.; Nayar, C. V. and Achuthan, N. R. (1992). Applying pattern recognition in distance relaying. Part 1: Concept. and Part 2: Feasibility. IEE Proceedings-C, Vol.139, No.4, pp.301-314.

Coury, D. V. and Jorge, D. C. (1998). Artificial neural network approach to distance protection. IEEE Transactions on Power Delivery (Jan.), Vol.13, No.1, pp.102-108.

Coury, D. V. and Oleskovicz, M. (1998). Multi-layer neural networks applied to distance relaying. International Journal of Electrical Power and Energy Systems, Elsevier Science, England, Vol.20, No. 8, pp. 539-542.

Dalstein T. and Kuliche, B. (1995). Neural network approach to fault classification for high speed protective relaying. IEEE Transmission on Power Delivery, Vol.10, No.2, pp.1002-1011.

Dalstein, T.; Friedrich, T.; Kuliche, B. and Sobajic, D. (1996). Multi neural network based fault area estimation for high speed protective relaying. IEEE Transactions on Power Delivery, Vol.11, No.2, pp.740-747.

Dillon, T. S. and Niebur, D. (1996). Neural networks applications in power systems. CRL Publishing, London, England.

Ghosh, A. K. and Lubkeman, D. L. (1995). The classification of power systems disturbance waveforms using a neural network approach. IEEE Transactions on Power Delivery, Vol.10, No.1, pp.109-115.

Kandil, N.; Sood, V. K.; Khorasani, K. and Patel, R. V. (1992). Fault identification in AC-DC transmission system using neural networks. Transactions on Power Systems, Vol.7, No.2, pp.812-819.

Kanoh, H.; Kaneta, M. and Kanemaru, K. (1991). Fault location for transmission lines using inference model neural network. Electrical Engineering in $\mathrm{Ja}$ pan, Vol.111, No. 7, pp.84-92.

Keerthipala, W. W. L.; Wai, C. T. and Huisheng, W. (1997). Neural network based classifier for power system protection. Electric Power Systems Research, Vol.42, pp.109-114. 
Kezunovic, M. and Rikalo, I. (1996). Detect and classify faults using neural nets. IEEE Computer Applications in Power, pp.42-47.

Khaparde, S. A.; Kale, P. B. and Agarwal, S. H. (1991). Application of artificial neural network in protective relaying of transmission lines. First International Forum on Application of Neural Networks to Power Systems, Seattle, WA, pp.139-143.

NeuralWorks Professional II/PLUS (1998). Version 5.23, NEURALWARE, a subsidiary of Aspen Technology, Inc.

Phadke, A. G. and Thorp, J. S. (1988). Computer relaying for power systems. England, Research Studies Press Ltd.

Sidhu, T. S.; Singh, H. and Sachdev, M. S. (1995). Design, implementation and testing of an artificial neural network based fault direction discriminator for protecting transmission lines. IEEE Transactions on Power Delivery, Vol.10, No.2, pp.697-706.

Stanley, H. H. e Phadke, A. G., Power system relaying. England, Research Studies Press Ltd., 1992.

Stevenson Jr., W. D. (1986). Elementos de análise de sistemas de potência. $2^{a}$ ed. Rio de Janeiro, McGraw-Hill do Brasil.

Su, W. B.; Mao, P. L.; Bo, Z. Q.; Aggarwal, R. K. and Johns, A. T. (1997). A fault detection technique for compositive transmission circuits using artificial neural networks. UPEC'97 - 32 ${ }^{\text {nd }}$ Universities Power Engineering Conference, Vol.1, pp.291294.

Yang, H.; Chang, W. and Huang, C. (1994). A new neural networks approach to on-line fault section estimation using information of protective relays and circuit breakers. IEEE Transactions on Power Delivery, Vol.9, No.1, pp.220-229. 